\title{
Trends in Antihypertensive Drug Use in Spanish Primary Health Care (1990- 2012)
}

Cáceres $M C^{1}$, Moyano $\mathrm{P}^{1}$, Fariñas $\mathbf{H}^{1}$, Cobaleda $\mathbf{J}^{\mathbf{1}, 2}$, Pijierro $\mathrm{A}^{\mathbf{1}}$, Dorado $\mathrm{P}^{1}$ and LLerena $\mathrm{A}^{\mathbf{1}^{*}}$

${ }^{1}$ CICAB Clinical Research Centre, Extremadura University Hospital and Medical School, Badajoz, Spain

${ }^{2}$ Ciudad Jardin Primary Health Care Center.SES Servicio Extremeño de Salud, Badajoz, Spain

\begin{abstract}
Objective: This study aimed to describe the use of antihypertensive in Extremadura (Spain) from 1990 to 2012 and its economic impact.

Method: Information on antihypertensive drug (ATC C02, C03, C07, C08, C09) utilization was obtained from the community pharmacy sales figures reimbursed by the Health System of Extremadura (Spain). Data were expressed in Defined Daily Dose (DDD) and DDD per 1000 inhabitants per day (DHD).

Results: Antihypertensive consumption in Extremadura increased from 67.1 DHD in 1990 to 315.2 in 2012 (an increase of 3.7 times). Agents acting on the Renin-Angiotensin System (C09) are responsible for $75 \%$ of the total increase. Since 2007 the use of Angiotensin II antagonist increased over ACE inhibitors.
\end{abstract}

Conclusions: The consumption of antihypertensive drugs in Extremadura increased remarkably in the last 23 years. In the last years the use of angiotensin II antagonist drugs is having a significant economic impact.

Keywords: Antihypertensives; Drug use; Pharmacoepidemiology; Primary care

\section{Introduction}

Hypertension is currently considered a major public health problem because of its importance as a cardiovascular risk factor. Worldwide, high blood pressure is estimated to cause 7.5 million deaths, about $12.8 \%$ of the total of all annual deaths [1]. Blood pressure levels have been shown to be positively and progressively related to the risk for stroke and coronary heart disease [2]. In addition to coronary heart diseases and stroke, complications of high blood pressure include heart failure, peripheral vascular disease, renal impairment, retinal haemorrhage and visual impairment [3].

The 33.3\% of adult population in Spain suffer from hypertension [4]. Moreover, 1 out of every 4 deaths and 1 out of every 2.5 deaths caused by cardiovascular disease is related to high blood pressure [5].

A great number of national and international guidelines for hypertension treatment have been published. The JNC 7 guideline recommended diuretics as first-line treatment in hypertension [6]. Therefore the current Guidelines advise that diuretics (including thiazides, chlorthalidone and indapamide), beta-blockers, calcium antagonists, Angiotensin-Converting Enzyme (ACE) inhibitors and angiotensin receptor blockers are all suitable for the initiation and maintenance of antihypertensive treatment, either as monotherapy or in some combinations [7].

The European guideline, on the other hand, suggests that unless a special indication exists, any of the five antihypertensive classes can be used as first-line treatment [8]. Although the number of prescriptions for Diuretics (Ds) and B-Blockers (BBs) is increasing, and for CalciumChannel Blockers (CCBs) is decreasing, in most countries the most frequently antihypertensive classes prescribed are still AngiotensinConverting Enzyme Inhibitors (ACEIs) or CCBs [9-15]. However, there is a considerable variation in the antihypertensive drug classes used in different countries [9-20].

The present study aimed to analyze the overall use and changes in the prescribing pattern of antihypertensive drugs by Family Medicine physicians in the Spanish region of Extremadura from 1990 to 2012, its compliance with guidelines, and its economic impact.

\section{Method}

In order to study the use of antihypertensive drugs in Extremadura, annual data from 1 January 1990 to 31 December 2012 about the prescribing of antihypertensive drugs were collected from the community pharmacy sales figures reimbursed by the Spanish Extremadura Health System (SES), which covers almost 100\% of the Extremadura population (1.100.000 inhabitants).

All the antihypertensive drugs marketed in Spain and listed in the Anatomic Therapeutic Chemical (ATC) classification system were studied. The ATC studied groups studied are the followings: C02 [Antihypertensives]; C03 [Diuretics]; C07 [Beta blocking agents]; C08 [Calcium channel blockers); C09 [Renin angiotensin system], including: C09A (Angiotensin-converting enzyme inhibitors (ACE inhibitors), C09B (ACE inhibitors, combinations), C09C (Angiotensin II antagonists), C09D (Angiotensin II antagonists, combinations).

Drug consumption figures were expressed as the number of Defined Daily Doses (DDD) per 1000 inhabitants per Day of Treatment (DHD), using the DDD values proposed by WHO [21].

Total costs were estimated by multiplying the number of sold

*Corresponding author: LLerena A, CICAB, Clinical Research Centre Extremadura University Hospital and Medical School, Badajoz 06080, Spain, Tel: +34924218040; Fax: +34924289675; E-mail: allerena@unex.es

Received November 05, 2014; Accepted January 05, 2015; Published January 06, 2015

Citation: Cáceres MC, Moyano P, Fariñas H, Cobaleda J, Pijierro A, Darado P,LLerena A (2015) Trends in Antihypertensive Drug Use in Spanish Primary Health Care (1990-2012). Adv Pharmacoepidemiol Drug Saf 3: 172 doi:10.4172/2167. 1052.1000172

Copyright: (c) 2015 Cáceres MC, et al. This is an open-access article distributed under the terms of the Creative Commons Attribution License, which permits unrestricted use, distribution, and reproduction in any medium, provided the original author and source are credited. 
Citation: Cáceres MC, Moyano P, Fariñas H, Cobaleda J, Pijierro A, Darado P,LLerena A (2015) Trends in Antihypertensive Drug Use in Spanish Primary Health Care (1990-2012). Adv Pharmacoepidemiol Drug Saf 3: 172. doi:10.4172/2167-1052.1000172

Page 2 of 4

packages of each product by the price of each one. Cost per day was calculated by dividing the total cost by the total DDD consumed for the active ingredient or subgroup considered.

Study limitations: firstly, data were collected by auditing drug sales in all the pharmacies of Extremadura, which allowed us to estimate the prescription of antihypertensive drugs but not their real use; [22] second, the DDD methodology allows the possibility of analyzing trends of consumption over the years, but does not allow individual level analyses regarding the real DDD received by a patient daily.

\section{Results}

Antihypertensive consumption in Extremadura increased fivefold between 1990 and 2012 (Figure 1). It is estimated that in 1990 there were 73,781 people in treatment with an antihypertensive drug, increasing to 346,726 people in 2012.

Subgroup C09 (agents acting on the renin-angiotensin system) is responsible for $75 \%$ of the total increase (Figure 1).

Since 2007 the use of ARBs $(\mathrm{C} 09 \mathrm{C}+\mathrm{C} 09 \mathrm{D})$ increased over ACE inhibitors $(\mathrm{C} 09 \mathrm{~A}+\mathrm{C} 09 \mathrm{~B})$ (Figure 2).

The ranking of the most frequently prescribed renine-angyotensine drugs (C09) in the study period is shown in Table 1.

Total spending on antihypertensives (C02, C03, C07, C08 and C09)

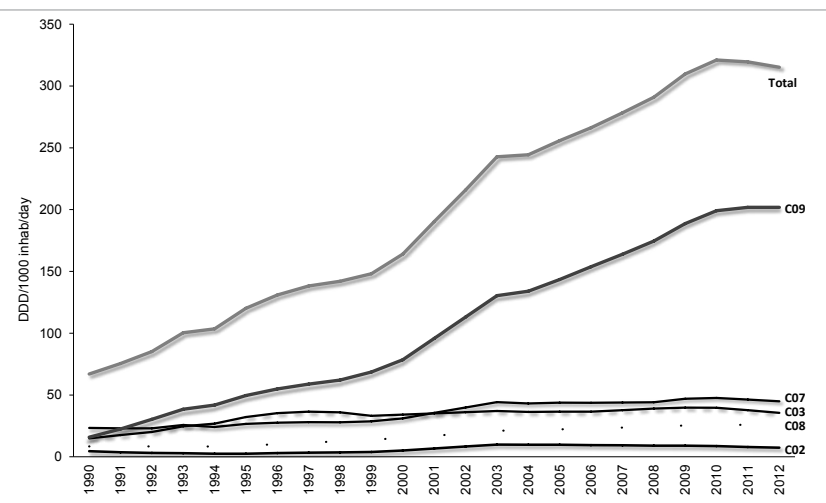

Figure 1: Antihypertensive drugs consumption in Extremadura, Spain (1990 2012).(C02 Antihypertensives; C03 Diuretics; C07 Beta-blockers; C08 Calcium channel blockers; C09 Agents acting on the renin-angiotensin system).

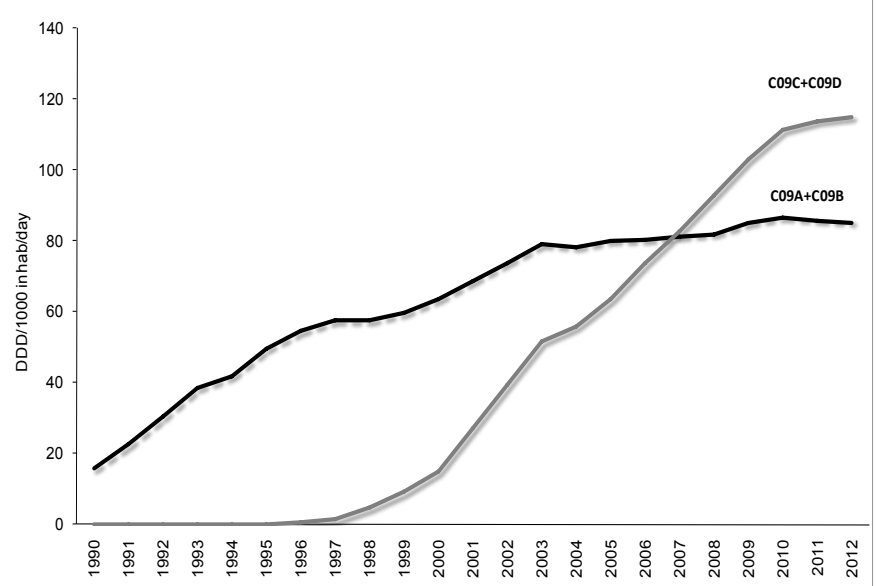

Figure 2: Angiotensin II antagonist (ARBs) and ACE inhibitors consumption in Extremadura, Spain (1990-2012)

\begin{tabular}{|c|c|c|c|c|c|}
\hline \multicolumn{2}{|c|}{1990} & \multicolumn{2}{c|}{2000} & \multicolumn{2}{c|}{2012} \\
\hline Drug & $\%$ & Drug & $\%$ & Drug & $\%$ \\
\hline Captopril & 49.6 & Enalapril & 31.3 & Enalapril & 18.3 \\
\hline Enalapril & 47.9 & Candesartan & 11.5 & Candesartan & 14.1 \\
\hline Captopril+diuretics & 2.4 & Ramipril & 7.0 & Ramipril & 12.2 \\
\hline & & Valsartan & 6.6 & Valsartan & 8.2 \\
\hline & & Olmesartan & 5.3 & Valsartan+diuretics & 4.8 \\
\hline
\end{tabular}

Table 1: Active ingredients most frequently prescribed in selected years, expressed in percentage of the total of the renin-angiotensin system drugs (C09). Combinations are fixed.

in 2012 was 42.5 million euros, of which $75.9 \%$ corresponds to the drug spending of the renin-angiotensin system (C09). Within this group, during the 2003-2012 spending on ACE inhibitors (C09A+C09B) decreased from 9.8 to 4.5 million euros, while in ARBs (C09C+C09D) increased from 22.1 to 27.0 million euros.

\section{Discussion}

There was an increase in the use of antihypertensive drugs in the study period, the same result was observed in similar studies performed in Spain [23-27]. This increase could be due to an increase in the number of people on antihypertensive treatment. It should be noted that antihypertensive drugs, except the $\mathrm{C} 02$ group, are not only used in hypertension, but also for treatment of other diseases such as diabetes, nephropathy, ischemic heart disease, peripheral arterial disease or stroke. Furthermore, the criteria for blood pressure control throughout the study period became more restrictive, considering as normal blood pressure values ever lower [6].Therefore, it is increasingly common to find patients taking more than one drug, and also patients that at the beginning of the study period would be considered normotensive, at period end would not be [6]. Other possible causes for the increase in the prescription of antihypertensives may be the aging population, changes in lifestyle, a better knowledge of the condition by the population, the implementation of Health Programmes at Primary Care. Furthermore must be taking into account the important role that have the implementation on recent years of the ambulatory blood pressure monitoring and home blood pressure monitoring, these measures have facilitated the diagnosis and the management of hypertension, and have strengthened its prognostic value.

Study data shows that the total use of antihypertensives in Extremadura is higher than in other studies performed in Spain [25-27]. Extremadura is among the regions with higher rates of cardiovascular morbidity and mortality [28] and a high incidence of diabetic nephropathy and microalbuminuria $[29,30]$ diseases that are related with the level of control of cardiovascular risk factors, particularly with high blood pressure. However, control of blood pressure in Extremadura is similar to the rest of Spain, 36.7\% [31,32].

This rising use of antihypertensive over the past 20 years is not exclusive to Spain, also occurred in other European countries $[33,34]$.

The increase in total use of antihypertensive drugs is mainly due to increased consumption of $\mathrm{C} 09$ group. The dramatic increase could be due to greater efficiency and tolerability of this group, although up today, clinical trials have failed to demonstrate greater efficacy and lower mortality of this group respect to others. Furthermore, it must be taken into account the possible influence of pharmaceutical companies. The C09 group is the most widely group used also in Europe, as it is shown in different European studies [33,34,38-40]. Within this group, the ACE inhibitors were the antihypertensive drugs most commonly used until 2007, at that moment they started to be replaced by ARBs. In a similar study published, in Murcia region the same fact is observed 
Citation: Cáceres MC, Moyano P, Fariñas H, Cobaleda J, Pijierro A, Darado P,LLerena A (2015) Trends in Antihypertensive Drug Use in Spanish Primary Health Care (1990-2012). Adv Pharmacoepidemiol Drug Saf 3: 172. doi:10.4172/2167-1052.1000172

since 2005 [27]. However Spanish data released shows that until 2006 the ACE inhibitors were the antihypertensive most prescribed [24].

Captopril was the active ingredient most widely used in 1990; from 1991 to the end of the study period, enalapril remained as the most active ingredient prescribed, even after the marketing of ACE inhibitor. This trend is also observed in other studies published $[25,26]$. Considering the causes of high consumption of enalapril, it should be noted that enalapril has a good tolerability and a long half-life which allows an adequate blood pressure control with a single daily dose; it is also worth noting that as its action mechanism was better known, enalapril began to be used in the treatment of other diseases such as heart failure in normotensive patients and the prevention of diabetic nephropathy in diabetic patients.

From the point of view of therapeutic recommendations, therapeutic guidelines agree on $\mathrm{D}_{\mathrm{s}}$ as first line treatment followed by $\mathrm{BB}_{\mathrm{s}}$. Since the commercialization of ACE inhibitors and CCBs, they became part of the first-line treatment. Since 1997, the JNC VI, recommended by the first time ARBs only when the ACE inhibitor is not tolerated, but in 2003, both the JNC VII and the ESH-ESC 1, added ARBs as first-line treatment [6-8,35-37].

Despite all the measures that were taken in recent years to reduce drug spending, the significant increase in the use of antihypertensive drugs in the study period generated a major economic impact on the healthcare system, being due largely to the high cost of ARBs. This fact has been observed in other studies $[24,27,33,40]$.

\section{References}

1. World Health Organization (2009) Global health risks: mortality and burden of disease attributable to selected major risks. Geneva, Switzerland.

2. Whitworth JA. World Health Organization, International Society of Hypertension Writing Group (2003) 2003 World Health Organization (WHO)/International Society of Hypertension (ISH) statement on management of hypertension. J Hypertens 21: 1983-1992.

3. Williams B, Poulter NR, Brown MJ, Davis M, Mclnnes GT, et al. (2004) British Hypertension Society guidelines for hypertension management 2004 (BHS-IV): summary.BMJ 328: 634-640.

4. Banegas JR, Graciani A, de la Cruz-Troca JJ, León-Muñoz LM, Guallar-Castillón $P$, et al. (2012) Achievement of cardiometabolic goals in aware hypertensive patients in Spain: a nationwide population-based study. Hypertension 60: 898905.

5. Banegas Banegas JR, Rodríguez-Artalejo F, de la Cruz Troca JJ, de Andrés Manzano B, del Rey Calero J (1999) Hypertension-related mortality and arterial pressure in Spain. Med Clin (Barc) 112: 489-494

6. Chobanian AV, Bakris GL, Black HR, Cushman WC, Green LA, et al. (2003) Seventh report of the Joint National Committee on Prevention, Detection, Evaluation, and Treatment of High Blood Pressure. Hypertension 42: 12061252

7. Mancia G, Fagard R, Narkiewicz K, Redon J, Zanchetti A, et al. (2013) 2013 ESH/ESC Guidelines for the management of arterial hypertension: The Task Force for the management of arterial hypertension of the European Society of Hypertension (ESH) and of the European Society of Cardiology (ESC). J Hypertens 31:1281-357.

8. European Society of Hypertension-European Society of Cardiology Guidelines Committee (2003) 2003 European Society of Hypertension-European Society of Cardiology guidelines for the management of arterial hypertension. J Hypertens 21: 1011-1053.

9. Chamontin B, Poggi L, Lang T, Ménard J, Chevalier H, et al. (1998) Prevalence treatment, and control of hypertension in the French population: data from a survey on high blood pressure in general practice, 1994. Am J Hypertens 11: 759-762.
10. Siegel D, Lopez J, Meier J, Cunninggham F (2001) Changes in the pharmacologic treatment of hypertension in the Department of Veterans Affairs 1997-1999: decreased use of calcium antagonists and increased use of betablockers and thiazide diuretics. Am J Hypertens 14: 957-962.

11. Sturani A, Degli Esposti E, Serra M, Ruffo P, Valpiani G; PANDORA Study Group (2002) Assessment of antihypertensive drug use in primary care in Ravenna, Italy, based on data collected in the PANDORA project. Clin Ther 24: 249-259.

12. Esposti LD, Baio GL, Valpiani G, Buda S, Sturani A, et al. (2002) Cost allocation in antihypertensive drug therapies. Expert Rev Pharmacoecon Outcomes Res 2: 419-426.

13. Rotmensch HH, Mendelevitch L, Silverberg DS, Liron M (1996) Prescribing pattern of antihypertensive drugs in the community. J Hum Hypertens 10 Suppl 3: S169-172.

14. Siddiqui S, Ogbeide DO, Karim A, Al-Khalifa I (2001) Hypertension control in a community health centre at Riyadh, Saudi Arabia. Saudi Med J 22: 49-52.

15. Crucitti A, Cecchi E, Gensini GF, Simone I, Conti A, et al. (2000) Use of antihypertensive drugs in the Italian hospitals. GIFA group. Gruppo Italiano di Farmacoepidemiologia nell'Anziano. Pharmacol Res 41: 249-253.

16. Wallenius S, Kumpusalo E, Pärnänen H, Takala J (1998) Drug treatment for hypertension in Finnish primary health care. Eur J Clin Pharmacol 54: 793-799.

17. Walley T, Duggan AK, Haycox AR, Niziol CJ (2003) Treatment for newly diagnosed hypertension: patterns of prescribing and antihypertensive effectiveness in the UK. J R Soc Med 96: 525-531.

18. Gasse C, Stieber J, Döring A, Keil U, Hense HW (1999) Population trends in antihypertensive drug use: results from the MONICA Augsburg Project 1984 to 1995. J Clin Epidemiol 52: 695-703.

19. Al Khaja KA, Sequeira RP (2006) Pharmacoepidemiology of antihypertensive drugs in primary care setting of Bahrain between 1998 and 2000. Pharmacoepidemiol Drug Saf 15: 741-748.

20. Jassim al Khaja KA, Sequeira RP, Wahab AW, Mathur VS (2001) Antihypertensive drug prescription trends at the primary health care centres in Bahrain. Pharmacoepidemiol Drug Saf 10: 219-227.

21. Uchida N, Chong MY, Tan CH, Nagai H, Tanaka M, et al. (2007) International study on antidepressant prescription pattern at 20 teaching hospitals and major psychiatric institutions in East Asia: Analysis of 1898 cases from China, Japan, Korea, Singapore and Taiwan. Psychiatry Clin Neurosci 61: 522-528.

22. Jones G (2003) Prescribing and taking medicines. BMJ 327: 819.

23. Jabary NS, Herrero AM, Gonzalez JA (2000) The use of antihypertensive therapy in Spain (1986-1994). Am J Hypertens 13: 607-610.

24. García del Pozo J, Ramos Sevillano E, de Abajo FJ, Mateos Campos R (2004) Use of antihypertensive drugs in Spain (1995-2001). Rev Esp Cardiol 57: 241249.

25. Prieto M, de Abajo FJ, Montero D, Martín-Serrano G, Madurga M, et al. (1998) Use of antihypertensive drugs in Spain, 1985-1995. Med Clin (Barc) 110: 247253

26. Montero D, García J, De Abajo FJ (2009) Use of Antihypertensive Drugs in Spain, 1992-2006. Essential Information System for Therapy and Health 1-14.

27. Ruiz JC, Ariza MA, Aguilera B, Leal M, Gómez R, et al. (2012) Analysis of the rational use of anti-hypertensives in the Murcia (Spain) region]. Aten Primaria 44: $272-279$

28. Comprehensive Plan for cardiovascular diseases of Extremadura. Merida: Junta de Extremadura (2007).

29. Robles NR, Cid MC, Roncero F, Pizarro JL, Sánchez-Casado E, et al. (1996) Incidence of diabetic nephropathy in the province of Badajoz along the period from 1990 to 1994. An Med Interna 13: 572-575.

30. Roberto Robles N, Velasco J, Mena C, Angulo E, Garrote T; MICREX Study (2006) Microalbuminuria in diabetic and hypertensive patients: a study of 979 patients. Med Clin (Barc) 127: 761-764.

31. Marcos G, Robles NR, Barroso S, Sánchez Muñoz-Torrero JF (2009) Blood pressure control in Extremadura control. Results from a study on Risk Contro Factors in Extremadura (CHEST study). Hipertens Vasc Risk 26: 14-19. 
Citation: Cáceres MC, Moyano P, Fariñas H, Cobaleda J, Pijierro A, Darado P,LLerena A (2015) Trends in Antihypertensive Drug Use in Spanish Primary Health Care (1990-2012). Adv Pharmacoepidemiol Drug Saf 3: 172. doi:10.4172/2167-1052.1000172

Page 4 of 4

32. Llisterri Caro JL, Rodríguez Roca GC, Alonso Moreno FJ, Banegas Banegas JR, González-Segura Alsina D, et al. (2008) Control of blood pressure in Spanish hypertensive population attended in primary health-care. PRESCAP 2006 Study. Med Clin (Barc) 130: 681-687.

33. Furtado C, Pinto M (2006) Anti-hypertensive drug utilization in Continental Portugal (1999-2004). Rev Port Cardiol 25: 273-292.

34. Rønning M, Sakshaug S, Strøm H, et al. (2009) Drug Consumption in Norway 2004-2008. Norwegian Institute of Public Health, Norway.

35. (1997) The sixth report of the Joint National Committee on prevention, detection, evaluation, and treatment of high blood pressure. Arch Intern Med 157: 2413-2446.

36. Mancia G, De Backer G, Dominiczak A, Cifkova R, Fagard R, et al. (2007) 2007 Guidelines for the Management of Arterial Hypertension: The Task Force for the Management of Arterial Hypertension of the European Society of Hypertension (ESH) and of the European Society of Cardiology (ESC). J Hypertens 25: 1105-1187.
37. Mancia G, Laurent S, Agabiti-Rosei E, Ambrosioni E, Burnier M, et al. (2009) Reappraisal of European guidelines on hypertension management: a European Society of Hypertension Task Force document. J Hypertens 27: 2121-2158.

38. Simó Miñana J (2012) Use of prescription drugs in Spain and Europe. Aten Primaria 44: 335-347.

39. Stolk P, Van Wijk BL, Leufkens HG, Heerdink ER (2006) Between-country variation in the utilization of antihypertensive agents: Guidelines and clinica practice. J Hum Hypertens 20: 917-922.

40. Vara L, Sangrador A, Muñoz P, Sanz S (2004) Use of antihypertensive agents in Cantabria, Spain [1995-2002]: discrepancy with the published evidence. Gac Sanit 18: 406-408 